\title{
Modeling and Simulation of Mission Planning Problem for Remote Sensing Satellite Imaging
}

\author{
Yao Pan ${ }^{1, a}$, Zhong Ming Chi ${ }^{1}$, Qi Long Rao ${ }^{1}$, Kai Peng Sun ${ }^{1}$ and Yi Nan Liu ${ }^{1}$ \\ ${ }^{1}$ Shanghai Institute of Satellite Engineering, Shanghai 201109, China
}

\begin{abstract}
Mission planning problem for remote sensing satellite imaging is studied. Firstly, the time constraint satisfaction problem model is presented after analyzing the characteristic of time constraint. Then, An optimal path searching algorithm based on the discrete time window is proposed according to the non-uniqueness for satellite to mission in the visible time window. Simulation results verify the efficiency of the model and algorithm.
\end{abstract}

\section{Introduction}

Remote sensing satellite can receive the information from the Earth sent by satellite borne senor in space, which have advantages of no constraint on any country, wide coverage, etc. They are widely applied in military reconnaissance, resources exploration, weather forecast and so forth. How to fulfill maximum imaging missions cooperatively through the effective strategy is the current problem of mission planning for remote sensing satellite[1].

The manoeuvrability of rolling and pitching can extend the visible time window for satellite to target compared with the satellite just rolling[2], and the imaging time window becomes a continuous selectivity variable. To tackle the problem of mission planning for remote sensing satellite, the characteristic of time constraint is analyzed. The time constraint satisfaction problem model is presented, and an optimal path searching algorithm is proposed.

\section{Analysis of time constraint}

Basic concepts in connection with time constraint are defined as follows:

- Definition 1 Visible time window means the time window visible for satellite to target all the time. The Euler Angle for satellite to target is bijective with time in visible time window.

- Definition 2 Imaging time window means the time window imaging for satellite to target. The Euler Angle for satellite to target is invariant in imaging time window.

Figure 1 shows the visible time window and imaging time window for satellite to target.

There are many similar constraints between satellite rolling and pitching and satellite just rolling, such as rolling angle constraint, pitching angle constraint, visible time window constraint and so forth[3-4]. No more details here. In this paper, time constraint is the main constraint to be discussed[5].

The characteristics of time constraint for remote sensing satellite mission planning problem are as follows:

${ }^{\mathrm{a}}$ Corresponding author e-mail: panyaopaper@outlook.com 
- The non-uniqueness of imaging time window for satellite to target. The imaging time window can be confirmed by imaging start time and imaging duration, and the imaging start time for satellite to target can be selected from the visible time window randomly.

- The non-uniqueness of imaging Euler Angle for satellite to target. The Euler Angle for satellite to target is changed with time in the visible time window, while it is invariant in the imaging time window. All illustrated in figure 1.

- The non-uniqueness of satellite attitude transition time between neighbouring targets. The attitude transition time between neighbouring targets can be confirmed by the imaging Euler Angles.

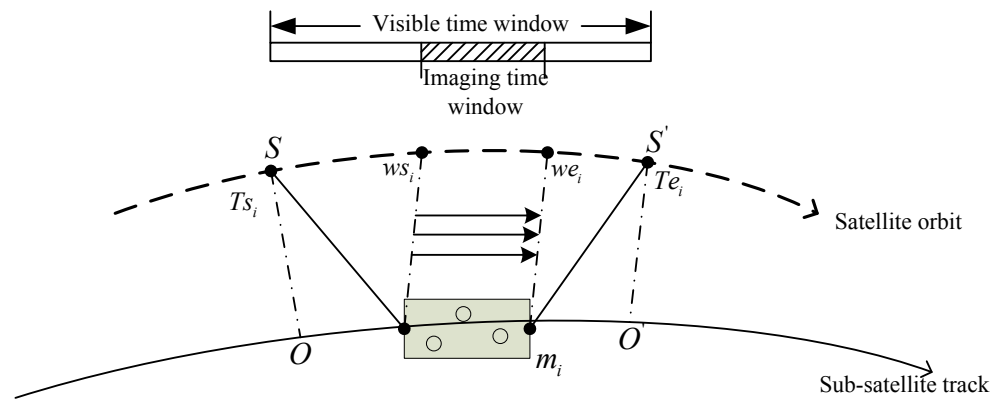

Figure 1. The visible time window and imaging time window for satellite to target

To confirm the imaging time window and imaging Euler Angle is the key problem in this article, and the imaging time window can be determined by imaging duration, while the imaging Euler Angle can be determined by imaging start time. So the problem is transformed into determining the imaging duration and imaging start time.

\section{Time constraint satisfaction problem model}

Time constraint satisfaction problem can be indicated by $\langle\boldsymbol{V}, \boldsymbol{D}, \boldsymbol{C}\rangle$ triples[6], where $\boldsymbol{V}$ is the set of imaging time windows for targets, $\boldsymbol{D}$ is the set of visible time windows for targets, and $\boldsymbol{C}$ is the set of constraint conditions, including time window constraint, drift angle adjusting time constraint, maximum imaging time constraint in single orbit, and attitude transition time constraint.

In the remote sensing satellite mission planning problem, the variables are involved as follows:

- The visible time window is given by $T W_{i}=\left[T s_{i}, T e_{i}\right]$ for mission $\mathrm{i}$, where $T s_{i}$ is the visible start time and $T e_{i}$ is the visible end time.

- The imaging time window is given by $t w_{i}=\left[w s_{i}, w e_{i}\right]$ for mission $\mathrm{i}$, where $w s_{i}$ is the imaging start time and $w e_{i}$ is the imaging end time.

- The imaging duration is assumed by Tcon $_{i}$ for mission i.

- The drift angle adjusting time is treated as a constant $T_{Q}$, and the maximum imaging time in single orbit is assumed by $T I M G_{\max }$.

- The maneuver rate of rolling and pitching are denoted as $\vartheta$ and $\rho$ separately.

Based on the above analysis of the problem, this paper establishes the time constraint satisfaction problem model (TCSPM) for remote sensing satellite mission planning, the mathematical description of the model and explanation are as follows: 
- $\quad E$ is the object of the optimization, which means to minimize the total energy consumed by satellite during the mission planning, including the energy consumed by maneuver and imaging. That is,

$$
E=\min \left(T_{\text {moving }} \times P_{\text {moving }}+T_{\text {imaging }} \times P_{\text {imaging }}\right)
$$

where $T_{\text {moving }}$ means the total time of attitude maneuver, $T_{\text {imaging }}$ means the total time of imaging, and $P_{\text {moving }}$ and $P_{\text {imaging }}$ are average power of maneuver and imaging.

- The constraint conditions consisting of equation (2)-(5):

$$
\begin{array}{r}
\forall i \in[1, n], T s_{i} \leq w s_{i} \leq w e_{i} \leq T e_{i} \\
T_{Q}=\text { constant } \\
T_{\text {imaging }}=\sum_{i=1}^{n} \text { Tcon }_{i} \leq T I M G_{\max } \\
w e_{i}+\max \left\{\frac{\left|\beta_{i}-\beta_{j}\right|}{\vartheta}+\frac{\left|q_{i}-q_{j}\right|}{\rho}\right\}+t_{s} \leq w s_{j}-T_{Q}
\end{array}
$$

where $\beta_{i}$ and $\beta_{j}$ are the rolling angles of mission $\mathrm{i}$ and $\mathrm{j}, q_{i}$ and $q_{j}$ are the pitching angles of mission $\mathrm{i}$ and $\mathrm{j}, t_{s}$ is the attitude stabilization time.

Equation (2) means the imaging time window for satellite to mission should be contained in the visible time window; Equation (3) shows the drift angle adjusting time is set to a constant[7]; Equation (4) is to ensure that the total imaging time of the satellite in single orbit could not exceed the upper limit; Equation (5) shows the required attitude transition time between neighbouring targets[8-9] (see figure 2).

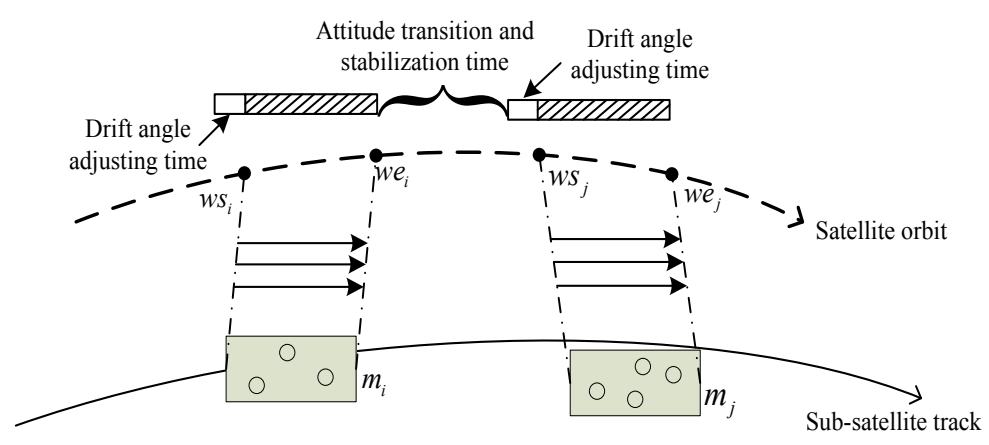

Figure 2. The constraint of attitude transition time for satellite

\section{Optimal path searching algorithm}

An optimal path searching algorithm based on the discrete time window is designed in this paper. Firstly, the visible time windows for planning missions need to be discrete according to certain fraction, generating a plurality of time points. Then, each time point is taken as the imaging start time. Lastly, the mature Hopfield neural network algorithm is used to search for the optimal path through continuous updating[10], and get the minimum energy consumption path.

Assumed that $\boldsymbol{M}=\left\{m_{1}, m_{2}, \cdots \cdots, m_{n}\right\}$ is the set of mission need to be planned, and $\boldsymbol{T} \boldsymbol{W}=\left\{\left[T s_{1}, T e_{1}\right],\left[T s_{2}, T e_{2}\right], \cdots \cdots,\left[T s_{n}, T e_{n}\right]\right\}$ is the set of visible time windows. The discrete fraction for visible time window is denoted as $a$. The steps of the algorithm are as follows: 
Step 1: Sorting the planning missions according to the visible time order for satellite to missions.

Step 2: Parting the visible time windows of the planning missions by discrete fraction $a$, and the visible time window is divided into $a$ parts, getting $a$ time points, and taking each time point as imaging start time for satellite to the mission (see figure 3).

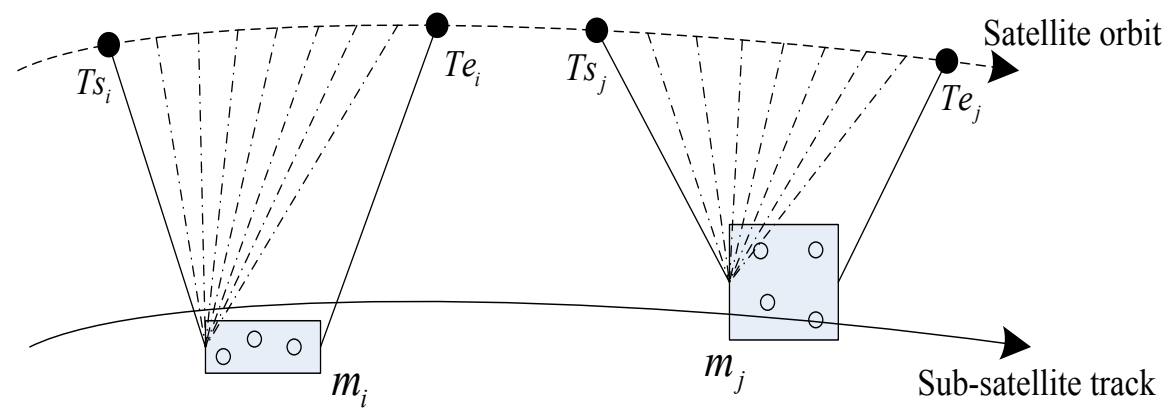

Figure 3. Discrete of visible time window

Step 3: Calculating the Euler Angle and imaging duration for each time point, and defining it as,

$$
\operatorname{point}(i, j)=\left(i, T s_{i}+\frac{T e_{i}-T s_{i}}{a} \times(j-1), \beta_{i j}, q_{i j}, T c o n_{i j}\right)
$$

where $\mathrm{i}$ is the mission $I D, j$ is the time point number, $T s_{i}+\frac{T e_{i}-T s_{i}}{a} \times(j-1)$ is the imaging start time, and $\beta_{i j}, q_{i j}$ and $T c o n_{i j}$ are the rolling angle, pitching angle and imaging duration for satellite to mission.

Step 4: Starting from each time point of the first mission according to the time point number, it is extended to the feasible time point of the following mission satisfied the constraint conditions.

Step 5: Using Hopfield neural network algorithm update the time point path from first mission to the last one according to the minimum energy principle, and getting the optimal path minimized energy and consumed constraint conditions.

Figure 4 shows flow of the optimal path searching algorithm.

\section{Simulation example}

The parameters of satellite and other constraints in simulation are shown in table 1 and table 2 .

Table 1. Parameters of remote sensing satellite

\begin{tabular}{cccccc}
\hline $\begin{array}{c}\text { Major semi } \\
\text { axis(km) }\end{array}$ & eccentricity & FOV(deg) & $\begin{array}{c}\text { Pitching } \\
\text { range(deg) }\end{array}$ & $\begin{array}{c}\text { Rolling } \\
\text { range(deg) }\end{array}$ & Manoeuvrability(deg/s) \\
\hline 7800 & 0.02 & 16.3 & \pm 40 & \pm 50 & 1.1 \\
\hline
\end{tabular}

Table 2. Parameters of other constraints

\begin{tabular}{cccc}
\hline $\begin{array}{c}\text { Average power of } \\
\text { attitude maneuver } \\
P_{\text {moving }}(\mathrm{w})\end{array}$ & $\begin{array}{c}\text { Average power of } \\
\text { imaging } P_{\text {moving }} \\
(\mathrm{w})\end{array}$ & $\begin{array}{c}\text { Drift angle adjusting } \\
\text { time } T_{Q}(\mathrm{~s})\end{array}$ & $\begin{array}{c}\text { Maximum imaging time in } \\
\text { single orbit } T I M G_{\max }(\mathrm{s})\end{array}$ \\
\hline 640 & 984 & 30 & 600 \\
\hline
\end{tabular}

A single orbit track was selected as the simulation scene, and the simulation start time was 03:41:17 March 23, 2016 (UTCG), the simulation end time was 05:28:32.6 March 23, 2016 (UTCG). 
The set of planning missions was presented with trips segmented by circular Areatarget[11] and missions clustered by point targets from $t_{1} \sim t_{18}[12]$. All shown in table 3 and table 4 .

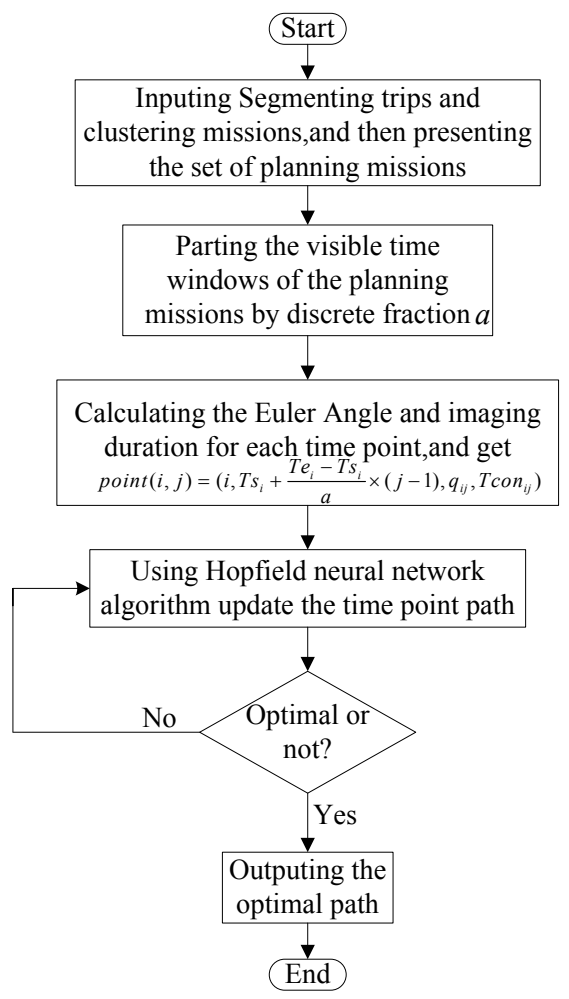

Figure 4. Flow of the optimal path searching algorithm

Table 3. Position of targets

\begin{tabular}{|c|c|c|c|c|c|}
\hline Target ID & Longitude and latitude & Note & Target ID & $\begin{array}{c}\text { Longitude and } \\
\text { latitude }\end{array}$ & Note \\
\hline$t_{1}$ & $\left(21.06^{\circ}, 42.56^{\circ}\right)$ & & $t_{10}$ & $\left(136.8^{\circ}, 34.46^{\circ}\right)$ & \\
\hline$t_{2}$ & $\left(7^{\circ}, 49^{\circ}\right)$ & & $t_{11}$ & $\left(129^{\circ}, 33^{\circ}\right)$ & \\
\hline$t_{3}$ & $\left(10^{\circ}, 49^{\circ}\right)$ & & $t_{12}$ & $\left(141.39^{\circ}, 15.04^{\circ}\right)$ & \\
\hline$t_{4}$ & $\left(8.63^{\circ}, 50.21^{\circ}\right)$ & & $t_{13}$ & $\left(145.21^{\circ}, 14.13^{\circ}\right)$ & \\
\hline$t_{5}$ & $\left(82^{\circ}, 45^{\circ}\right)$ & & $t_{14}$ & $\left(144.75^{\circ}, 13.4^{\circ}\right)$ & \\
\hline$t_{6}$ & $\left(90^{\circ}, 47^{\circ}\right)$ & & $t_{15}$ & $\left(148.14^{\circ},-22.9^{\circ}\right)$ & \\
\hline$t_{7}$ & $\left(128^{\circ}, 35^{\circ}\right)$ & & $t_{16}$ & $\left(152.77^{\circ},-25.4^{\circ}\right)$ & \\
\hline$t_{8}$ & $\left(132^{\circ}, 34.62^{\circ}\right)$ & & $t_{17}$ & $\left(152.2^{\circ},-27.88^{\circ}\right)$ & \\
\hline$t_{9}$ & $\left(121^{\circ}, 24^{\circ}\right)$ & & $t_{18}$ & $\left(151.2^{\circ},-33.13^{\circ}\right)$ & \\
\hline Areatarget & $\left(85.6^{\circ}, 54.7^{\circ}\right)$ & Radius $=550 \mathrm{~km}$ & & & \\
\hline
\end{tabular}


Table 4. Set of planning missions

\begin{tabular}{cccccc}
\hline $\begin{array}{c}\text { Mission } \\
\text { type }\end{array}$ & $\begin{array}{c}\text { Mission } \\
\text { ID }\end{array}$ & $\begin{array}{c}\text { Visible time } \\
\text { window }\end{array}$ & $\begin{array}{c}\text { Imaging time } \\
\text { window }\end{array}$ & $\begin{array}{c}\text { Rolling } \\
\text { angle(deg) }\end{array}$ & $\begin{array}{c}\text { Pitching } \\
\text { angle(deg) }\end{array}$ \\
\hline $\begin{array}{c}\text { Segmenting } \\
\text { trips }\end{array}$ & $m_{1}$ & $\backslash$ & $04: 07: 58 \sim 04: 11: 01$ & -15.983 & 31.23 \\
\hline$m_{2}$ & $\backslash$ & $04: 12: 42 \sim 04: 15: 51$ & -32.233 & -28.36 \\
\hline $\begin{array}{c}\text { Clustering } \\
\text { missions }\end{array}$ & $m_{3}$ & $03: 55: 33 \sim 04: 00: 16$ & $\backslash$ & -0.89 & $\backslash$ \\
& $m_{5}$ & $04: 08: 35 \sim 04: 17: 08$ & $\backslash$ & -44.925 & $\backslash$ \\
& $m_{6}$ & $04: 27: 08 \sim 04: 33: 45$ & $\backslash$ & 10.555 & $\backslash$ \\
\hline
\end{tabular}

As in table 4, the imaging Euler Angles for segmenting trips are already confirmed, so its time window needn't to be discrete.

The searching capability of the proposed optimal path searching algorithm is related to the degree of discretization for visible time window. For the traditional mission planning methods, the greater the degree of discretization, the better the astringency of the optimal solution, and the computing resources on the ground can also meet the requirements. As for the autonomous mission planning, computing resources is limited for satellite, and if the degree of discretization is set too high, it will increase the amount of computation. On the contrary, if the degree of discretization is set too small, it will not guarantee the astringency of the optimal solution. This is also the difference between the autonomous mission planning on the satellite and the traditional mission planning on the ground.

Therefore, in this paper, the simulation was analyzed through setting different numbers to find a relatively suitable number of discrete fraction. And then, the suitable number was taken as the degree of discretization to get the relatively optimal solution, which can reduce the amount of computation, but also can guarantee the astringency of the solution.

Different numbers of discrete fraction were $5,10,20,50$, and the 5 fraction was taken as an example to introduce the solving process of the algorithm.

Firstly, the visible time windows of the planning missions were parted by 5 discrete fractions, and then the imaging pitch angle and imaging duration for each time point were calculated by using STK. Table 5 shows the information of each time point.

Table 5. Information of each time point

\begin{tabular}{|c|c|c|c|c|c|c|}
\hline $\begin{array}{l}\text { Mission } \\
\text { ID }\end{array}$ & $\begin{array}{l}\text { Visible time } \\
\text { window }\end{array}$ & Time point & $\begin{array}{l}\text { Imaging } \\
\text { start time }\end{array}$ & $\begin{array}{c}\text { Imaging } \\
\text { duration(s) }\end{array}$ & $\begin{array}{l}\text { Pitching } \\
\text { angle(deg) }\end{array}$ & $\begin{array}{c}\text { Rolling } \\
\text { angle(deg) }\end{array}$ \\
\hline \multirow{5}{*}{$m_{3}$} & \multirow{5}{*}{$03: 55: 33 \sim 04: 00: 16$} & point $(3,1)$ & $03: 55: 33$ & 38.7 & 34.85 & \multirow{5}{*}{-0.89} \\
\hline & & point $(3,2)$ & $03: 56: 29.6$ & 36 & 20.87 & \\
\hline & & point $(3,3)$ & $03: 57: 26.2$ & 34.6 & 2.8 & \\
\hline & & point $(3,4)$ & $03: 58: 22.8$ & 35.7 & -16.2 & \\
\hline & & point $(3,5)$ & $03: 59: 19.4$ & 39.1 & -31.5 & \\
\hline \multirow{4}{*}{$m_{4}$} & \multirow{4}{*}{ 04:08:35 04:17:08 } & point $(4,1)$ & $04: 15: 51$ & 40.4 & -27.4 & \multirow{4}{*}{-44.925} \\
\hline & & point $(4,2)$ & $04: 16: 6.4$ & 34.5 & -28.6 & \\
\hline & & point $(4,3)$ & $04: 16: 21.8$ & 32.2 & -30.1 & \\
\hline & & point $(4,4)$ & $04: 16: 37.2$ & 28.1 & -31.4 & \\
\hline
\end{tabular}




\begin{tabular}{|c|c|c|c|c|c|c|}
\hline $\begin{array}{l}\text { Mission } \\
\text { ID }\end{array}$ & $\begin{array}{l}\text { Visible time } \\
\text { window }\end{array}$ & Time point & $\begin{array}{l}\text { Imaging } \\
\text { start time }\end{array}$ & $\begin{array}{c}\text { Imaging } \\
\text { duration(s) }\end{array}$ & $\begin{array}{l}\text { Pitching } \\
\text { angle(deg) }\end{array}$ & $\begin{array}{c}\text { Rolling } \\
\text { angle(deg) }\end{array}$ \\
\hline & & point $(4,5)$ & $04: 16: 52.6$ & 24.4 & -32.6 & \\
\hline \multirow{5}{*}{$m_{5}$} & \multirow{5}{*}{ 04:20:13 04:24:09 } & point $(5,1)$ & $04: 20: 13$ & 52.5 & 34.5 & \multirow{5}{*}{10.555} \\
\hline & & point $(5,2)$ & $04: 21: 0.2$ & 52.3 & 25.4 & \\
\hline & & point $(5,3)$ & $04: 21: 47.4$ & 48.7 & 15 & \\
\hline & & point $(5,4)$ & $04: 22: 34.6$ & 48 & 2.5 & \\
\hline & & point $(5,5)$ & $04: 23: 21.8$ & 41.3 & -10.4 & \\
\hline \multirow{5}{*}{$m_{6}$} & \multirow{5}{*}{$04: 27: 08 \sim 04: 33: 45$} & point $(6,1)$ & $04: 27: 8$ & 32.6 & 36.4 & \multirow{5}{*}{21.95} \\
\hline & & point $(6,2)$ & $04: 28: 27.4$ & 42 & 23 & \\
\hline & & point $(6,3)$ & $04: 29: 46.8$ & 50.2 & 4.55 & \\
\hline & & point $(6,4)$ & $04: 31: 6.2$ & 67 & -15.2 & \\
\hline & & point $(6,5)$ & $04: 32: 25.6$ & 84.4 & -31.4 & \\
\hline
\end{tabular}

According to the information of each time point in table 5, the optimal path consumed minimum energy was calculated by using Hopfield neural network algorithm. That is,

$$
\bigcirc \rightarrow \text { point }(3,3) \rightarrow m_{1} \rightarrow m_{2} \rightarrow \operatorname{point}(4,4) \rightarrow \operatorname{point}(5,5) \rightarrow \operatorname{point}(6,3)
$$

Assumed that the initial Euler Angle for satellite starts from zero, and the Euler Angle for satellite along the direction of sub-satellite track is positive when rolling to left or pitching forward, and negative when rolling to right or pitching backward. Table 6 is the command sequence of attitude maneuver for satellite in the optimal path.

Table 6. Command sequence of attitude maneuver

\begin{tabular}{ccccc}
\hline Mission ID & Imaging time window & Rolling angle(deg) & Pitching angle(deg) & $\begin{array}{c}\text { Maneuver } \\
\text { time(s) }\end{array}$ \\
\hline$m_{3}$ & $03: 57: 26.2 \sim 03: 58: 0.8$ & -0.89 & 2.8 & 3.321 \\
$m_{1}$ & $04: 07: 58 \sim 04: 11: 1$ & -15.983 & 31.23 & 39.171 \\
$m_{2}$ & $04: 12: 42 \sim 04: 15: 51$ & -32.233 & -28.36 & 68.256 \\
$m_{4}$ & $04: 16: 37.2 \sim 04: 17: 5.3$ & -44.925 & -31.4 & 14.159 \\
$m_{5}$ & $04: 23: 21.8 \sim 04: 24: 3.1$ & 10.555 & -10.4 & 68.832 \\
$m_{6}$ & $04: 29: 46.8 \sim 04: 30: 37$ & 21.95 & 4.55 & 23.711 \\
\hline $\begin{array}{c}\text { Total imaging } \\
\text { time(s) }\end{array}$ & 544.2 & Total attitude & 217.45 \\
\hline
\end{tabular}

As in table 6, when the discrete fraction is 5 , the total imaging time for satellite is 544.2 seconds satisfied the maximum imaging time in single orbit that the total imaging time of the satellite in single orbit could not exceed 600 seconds. The total attitude maneuver time is 217.45 seconds, and the total energy consumed by optimal path is $674.66 \mathrm{~kJ}$.

According to the above process, the total imaging time, total attitude maneuver time and total energy consumed in optimal path for 10,20, and 50 fractions were calculated. All shown in table 7 and table 8 . 
It can be seen from table 8, with the increase of discrete fraction, the total imaging time for satellite to planning missions remained steady, the total attitude maneuver time dropped off, and the energy consumed reduced gradually too. Figure 5 shows the relationships between the total energy consumed by satellite in optimal path and the degree of discretization for time window.

Table 7. The optimal path for different fraction

\begin{tabular}{cc} 
Fraction & Optimal path \\
\hline 5 & $\bigcirc \rightarrow$ point $(3,3) \rightarrow m_{1} \rightarrow m_{2} \rightarrow \operatorname{point}(4,4) \rightarrow \operatorname{point}(5,5) \rightarrow \operatorname{point}(6,3)$ \\
10 & $\bigcirc \rightarrow \operatorname{point}(3,4) \rightarrow m_{1} \rightarrow m_{2} \rightarrow \operatorname{point}(4,7) \rightarrow \operatorname{point}(5,9) \rightarrow \operatorname{point}(6,6)$ \\
20 & $\bigcirc \rightarrow \operatorname{point}(3,4) \rightarrow m_{1} \rightarrow m_{2} \rightarrow \operatorname{point}(4,14) \rightarrow \operatorname{point}(5,17) \rightarrow \operatorname{point}(6,12)$ \\
50 & $\bigcirc \rightarrow \operatorname{point}(3,10) \rightarrow m_{1} \rightarrow m_{2} \rightarrow \operatorname{point}(4,33) \rightarrow \operatorname{point}(5,42) \rightarrow \operatorname{point}(6,29)$ \\
\hline
\end{tabular}

Table 8. The calculating results for different fraction

Fraction Total imaging time (s)

Total attitude maneuver time (s)

Total energy consumed $(\mathrm{kJ})$

\begin{tabular}{llll}
\hline 5 & 544.2 & 217.45 & 674.66 \\
10 & 541.9 & 208.41 & 666.61 \\
20 & 542.2 & 204.65 & 664.50 \\
50 & 542.7 & 203.64 & 664.35 \\
\hline
\end{tabular}

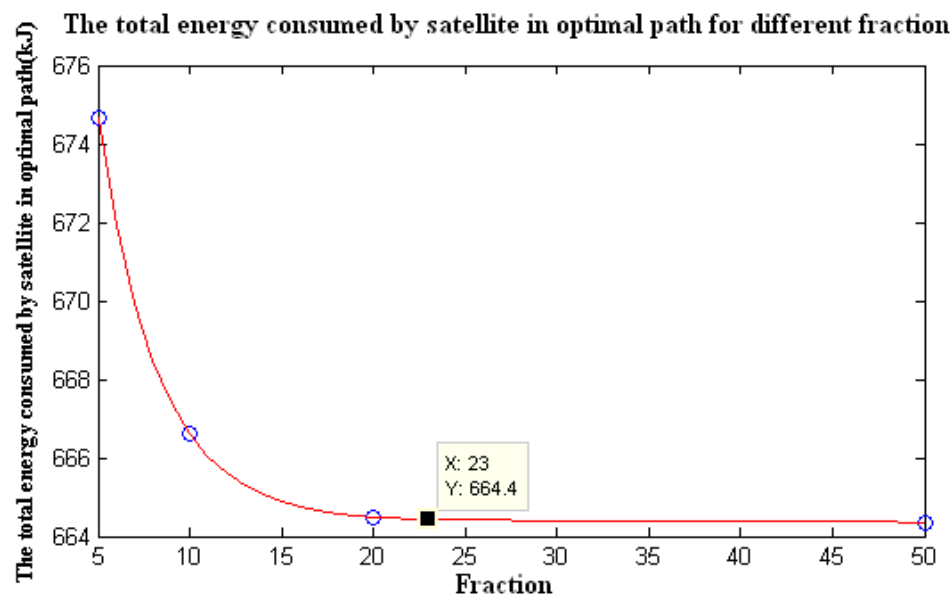

Figure 5. The total energy consumed by satellite in optimal path for different fraction

As in figure 5, with the increase of discrete fraction, the total energy consumed by satellite is convergent, and when the fraction comes to 23 , the total energy consumed has remained unchanged basically, the total energy keeps $644.40 \mathrm{~kJ}$. Therefore, the best discrete fraction can be set to 23 , and the corresponding optimal path is,

$$
\bigcirc \rightarrow \text { point }(3,6) \rightarrow m_{1} \rightarrow m_{2} \rightarrow \operatorname{point}(4,15) \rightarrow \operatorname{point}(5,19) \rightarrow \operatorname{point}(6,14)
$$

Table 9 shows the command sequence of attitude maneuver for the best discrete fraction.

Table 9. Command sequence of attitude maneuver for the best discrete fraction 


\begin{tabular}{ccccc}
\hline Mission ID & Imaging time window & Rolling angle(deg) & Pitching angle(deg) & $\begin{array}{c}\text { Maneuver } \\
\text { time(s) }\end{array}$ \\
\hline$m_{3}$ & $03: 56: 34.5 \sim 03: 57: 2.8$ & -0.89 & 19.2 & 18.081 \\
$m_{1}$ & $04: 07: 58 \sim 04: 11: 1$ & -15.983 & 31.23 & 24.411 \\
$m_{2}$ & $04: 12: 42 \sim 04: 15: 51$ & -32.233 & -28.36 & 68.256 \\
$m_{4}$ & $04: 16: 37.9 \sim 04: 17: 6.3$ & -44.925 & -31.3 & 14.069 \\
$m_{5}$ & $04: 23: 18.4 \sim 04: 23: 58.7$ & 10.555 & -9.7 & 69.372 \\
$m_{6}$ & $04: 30: 42.9 \sim 04: 31: 38$ & 21.95 & -9.6 & 10.346 \\
\hline Total imaging & 542.1 & \multicolumn{2}{c}{ Total attitude } \\
time(s) & \multicolumn{4}{c}{ maneuver time(s) } \\
\hline
\end{tabular}

According to the data in table 9, the total energy consumed for the best fraction 23 was calculated to be $664.27 \mathrm{~kJ}$, and there is little difference compared with the result as $664.40 \mathrm{~kJ}$ obtained by figure 5. Therefore, the result calculated for fraction 23 can be taken as the optimal solution of the mission planning problem.

Figure 6 shows the attitude maneuver strategy of satellite. Assumed that the attitude maneuver is carried out immediately after completing the imaging missions for satellite.

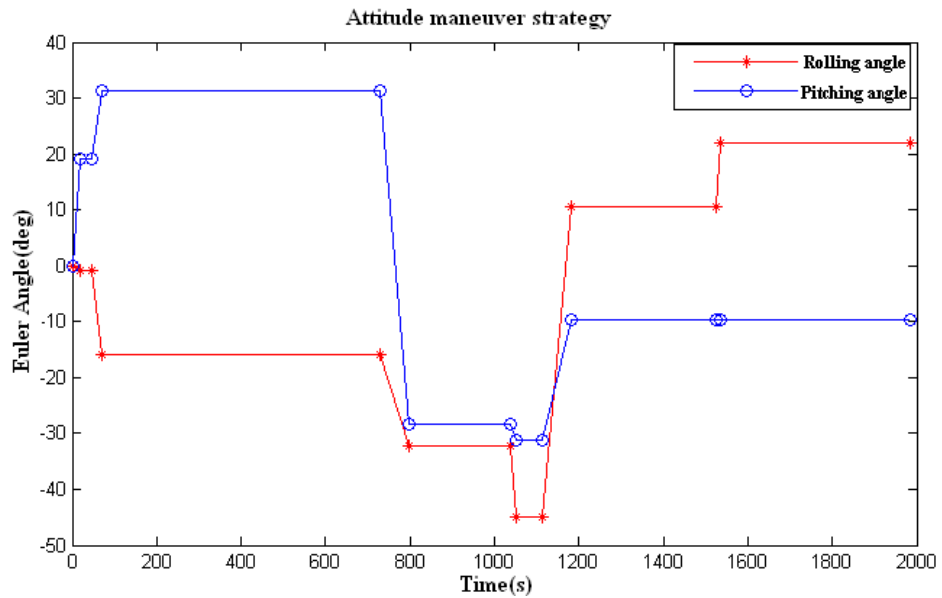

Figure 6. Attitude maneuver strategy of satellite for mission planning problem

\section{Conclusion and future work}

The mission planning problem for remote sensing satellite imaging is studied from the time constraint. The time constraint satisfaction problem model is presented, and an optimal path searching algorithm based on the discrete time window is proposed. Simulation results show that the proposed algorithm can meet the requirement of minimum consumed energy, but also can reduce the computation and improve the speed of mission planning.

Considering that the best discrete fraction is variable even for the same satellite, and the future work is analysing the influence factors of the best discrete fraction from orbit altitude, orbit inclination, satellite mass, satellite inertia, etc, and establishing the relationship between the best fraction and influence factors. 


\section{Acknowledgments}

This work was supported by the National Key Research and Development Program of China under Grant 2016YFB0500203, and the National Natural Science Foundation of China under Grants 11602145 and 51601116.

\section{References}

1. Wang Chong, Li Jun, Jing Ning, Wang Jun and Chen Hao. A Distributed Cooperative Dynamic Task Planning Algorithm for Multiple Satellites Based on Multi-agent Hybrid Learning, Chinese Journal of Aeronautics 24, 493-505 (2011)

2. Xiang Reng Xiang. Research on Selecting and Scheduling Observation of Agile Satellites , National University of Defence Technology (Changsha) 2 , 13-15 (2010)

3. Gerard Verfaillie and Thomas Schiex. Solution Reuse in Dynamic Constraint Satisfaction Problem, Proceeding of the Twelfth Conference of the American Association of Artificial Intelligence (Washington) 1, 307-312 (1994)

4. D Song, A Frank and Van Der Stappen, etc . An Exact Algorithm Optimizing Coverage Resolution for Automated Satellite Frame Selection , Proceeding of the IEEE International Conference on Robotics and Automation, 63-70 (2004)

5. Lian Zhen Yu, Tan Yue Jin and Yan Zhen Zhen . Temporal Reasoning Technology for AEOS Scheduling, Systems Engineering and Electronics 35, 1206-1211 (2013)

6. Ren Ming Kang . Adaptive Ant Colony Optimization for Constraint Satisfaction Problem , Northeastern University (Shenyang) 2, 9-10 (2014)

7. Yu Tao, Xu Shu Yan and Han Cheng Shan . Batch-type Real-time Adjustment for Drift Angle of Space Camera , Optics Precision Engineering 17, 1908-1914 (2009)

8. Michel Lemaitre, Gerard Veraillie, Frank Jouhaud and Jean Michel Lachiver . Selecting and Scheduling Observations of Agile Satellites , Aerospace Science and Technologyl 6 , 367-381 (2002)

9. Guo Hao, Qiu Di Shan and Huang Wei . Simulation to Impact of Attitude Changing Duration on Tasks Scheduling of An Agile Imaging Satellite, Journal of the Academy of Equipment Command \& Technology $23,70-74$ (2012)

10. Yu Sheng Wei . Case Analysis and Application of MATLAB Optimization Algorithm ed Cui Jing (Beijing: Tsinghua University Press) 18 , 262-271 (2015)

11. Pan Yao, Chi Zhong Ming, Rao Qi Long and Luo Da . Dynamic Segmenting Method of Polygon Target Based on FOV for Remote Sensing Satellite Imaging, Spacecraft Engineering vol 26, 38$42(2017)$

12. Guo Hao, Wu Guo Hua and Qiu Di Shan . Intensive Task Clustering Method for Agile Imaging Satellites, Systems Engineering and Electronics 34, 931-935 (2012) 